\title{
Reverse left ventricular remodeling is more likely in non ischemic cardiomyopathy patients upgraded to biventricular stimulation after chronic right ventricular pacing
}

Maria-Aurora Morales ${ }^{1 *}$, Umberto Startari ${ }^{2}$, Giuseppe Rossi ${ }^{1}$, Luca Panchetti ${ }^{2}$, Andrea Rossi ${ }^{2}$ and Marcello Piacenti ${ }^{1}$

\begin{abstract}
Background: Chronic right ventricular (RV) apical pacing may lead to left ventricular (LV) dyssynchrony and LV dysfunction. In heart failure due to RV pacing, upgrading to biventricular stimulation (CRT) can improve NYHA Class and LV function. A proportion of patients do not respond to upgrading. Aim was to assess whether etiology of LV dysfunction accounts for responses to CRT in RV-paced patients.
\end{abstract}

Methods: Sixty-two patients treated by CRT, under RV pacing from $50.2 \pm 5.4$ months, were studied. Cause of LV dysfunction was non-ischemic (NIC) in 28 and ischemic cardiomyopathy (IC) in 34 patients. Clinical and conventional echocardiographic parameters were available within 1 month before RV pacing, within 1 month before CRT and at $12 \pm 2$ months of follow-up (FU).

Results: Decreased LVEF (from $37.0 \pm 8.8$ to $25.6 \pm 6.1 \%, p<0.001$ ), increased LV end-systolic dimensions (LVESD) (from $48.1 \pm 8.6$ to $55.2 \pm 7.9 \mathrm{~mm}, \mathrm{p}<0.001$ ) and worsened NYHA Class (from $1.9 \pm 1.1$ to $3.2 \pm .6, \mathrm{p}<0.005$ ) were found before CRT, compared to pre RV-pacing. After CRT, 44/62 patients showed a $\geq 1$ NYHA Class improvement; $>10 \%$ decrease in LVESD was observed in 24 patients: 5 with IC, 19 with NIC $(p<.0 .001)$. The association between cause of LV dysfunction with $>10 \%$ decrease in LVESD remained highly significant $(p<0.001)$ adjusting for pre-CRT QRS duration, NYHA Class, LVEF, LVESD, treatment or RV pacing duration.

Conclusions: CRT improves functional class even after long-lasting pacing. Reverse remodeling is evident in a small population, more likely with NIC.

Keywords: congestive heart failure, biventricular stimulation, non-ischemic cardiomyopathy, ischemic cardiomyopathy

\section{Background}

Cardiac resynchronization therapy (CRT) is an established treatment for patients with drug refractory heart failure (HF) and left bundle branch block (LBBB) since it improves symptoms, quality of life and functional capacity $[1,2]$, leading to reduction of hospitalizations for heart failure and death $[3,4]$.

Like native left bundle branch block (LBBB), right apical ventricular (RV) pacing may result in intra- and interventricular dyssynchrony and development of LV

\footnotetext{
* Correspondence: morales@ifc.cnr.it

${ }^{1}$ CNR Clinical Physiology Institute, via G Moruzzi 1, 56124 Pisa, Italy

Full list of author information is available at the end of the article
}

remodeling due to an abnormal sequence of left ventricular activation [5-11].

Upgrading to CRT in RV paced patients has been shown to determine symptomatic and functional improvement comparable to that observed in non-paced LBBB patients [12-15]. Upgrading may also induce significant reverse remodeling in pacemaker-dependent patients [15]. However, until now, the clinical settings and conditions for upgrading conventional RV pacing to resynchronization have not been defined [16]: a percentage of patients still do not respond to upgrading, and conflicting results are reported on the role of underlying 
pathology in response to CRT in RV apical-paced patients $[14,15]$.

In patients with ischemic cardiomyopathy CRT leads to a less significant improvement in left ventricular ejection fraction and reduction in left ventricular end-systolic volume than in patients with non-ischemic disease at mid-and long-term follow-up $[17,18]$.

Therefore, the aim of this study was to assess whether the underlying cause of LV dysfunction may influence CRT-induced LV reverse remodeling in patients already under conventional RV apical pacing.

\section{Methods}

Patient population. We retrospectively studied 62 consecutive patients admitted to our Institute for upgrading to biventricular pacing from April 2007 to December 2009 in sinus rhythm or atrial paced rhythm. Criteria for implantation were represented by NYHA Class $=>$ III and LVEF < 35\% under optimal medical therapy. Among patients with history of ischemic heart disease, only those with no active ischemia, assessed by either myocardial scintigraphy or dypiridamole echocardiography within 2 weeks before LV lead implant, and who had no indications to coronary revascularization, were enrolled in the study.

Fifty-one were males, mean age $73 \pm 1.0$ years; all patients were under continuous RV apical pacing for $51.2 \pm 38.9$ months (range 3 to 170 months), with mean QRS duration $180 \pm 20 \mathrm{msec}$. At time of hospital admission patients were in NYHA Class III (n. 38) or IV (n.14) and were under optimal therapy with diuretics, ACE inhibitors or ATII blockers and beta blockers at maximal tolerated dosages before upgrading. Forty-eight patients were also under antialdosterone treatment.

Before upgrading, patients were defined as having ischemic cardiomyopathy (IC) if they had a history of myocardial infarction, and/or a history of coronary artery by-pass graft and/or angioplasty and/or a coronary angiogram indicating major disease. Patients were diagnosed as having non ischemic cardiomyopathy when no coronary artery disease could be detected by coronary angiography, significant valvular disease by conventional echocardiography and there was no documentation of myocarditis in their clinical history. On this basis the underlying cause of LV dysfunction was non-ischemic cardiomyopathy (NIC) in 28 and IC in 34 patients.

Seventeen patients had an implantable cardioverter defibrillator (ICD) that was upgraded to a CRT device, 35 patients had a pacemaker upgraded to CRT-Pace maker and 10 to CRT-Defibrillator.

LV leads were implanted by a transvenous approach through the coronary sinus and positioned in a posterolateral, lateral or anterolateral cardiac vein. LV lead position was assessed by an experienced radiologist and cardiologist in all patients before hospital discharge. In all patients the devices were programmed in rate responsive dual-chamber mode, and atrio-ventricular delay was optimized before discharge by a previously published method which takes into account the Doppler derived $\mathrm{dP} / \mathrm{dt}$ by the mitral regurgitation jet [19].

\section{Echocardiographic examination}

A standard transthoracic echocardiogram was performed by commercially available instruments (Acuson Sequoia, Acuson Corporation, Mountain View, CA, USA; Vivid system 7, GE/Vingmed, Milwakee, WI, USA). LV enddiastolic dimensions (LVEDD) and LV end-systolic dimensions (LVESD) were obtained from M-mode recordings derived from $2 \mathrm{D}$ echocardiograms of the $\mathrm{LV}$ transverse axis. These were obtained using the parasternal long axis approach with the M-mode cursor positioned at the tips of the mitral valve leaflets, using the leading-edge methods, according to recommendations of the American Society of Echocardiography. LV end-diastolic and systolic volumes and derived ejection fraction were assessed by the biplane summation method from the apical 4-chamber view [20].

Clinical and functional parameters by 2D echocardiography were available in all patients in three conditions: 1) within 1 month before first implant of RV pacing, 2) within 1 month before implantation of the LV lead and 3 ) at a mean of $12 \pm 4$ months follow-up (FU) after CRT. Before CRT, wall motion score index was also calcutated in all patients and mitral regurgitation severity determined semiquantitatively from color Doppler images obtained from the conventional parasternal long axis and apical views using the regurgitant jet area to LA area ratio [21]. The following score was used: 1: mild regurgitation, 2: moderate and 3: severe insufficiency. All echocardiograms were recorded and stored for off-line analysis by two reviewers blind to patient name and date of examination.

The investigation conforms with the principles outlined in the Declaration of Helsinki (Br 6 Med J 1964, ii:177).

\section{Statistical analysis}

Results are presented as means $\pm \mathrm{SD}$. Changes in continuous variables before and after procedures were compared using paired Student's t-test. Analysis of variance was performed for comparing data between patients with NIC or IC and between patients with and without reverse remodeling. The chi-square test was used to compare categorical variables. A multiple logistic regression was used to assess the association between etiology (NIC or IC) and LV remodeling, categorized as $>10 \%$ or $<=10 \%$ decrease in LVESD, adjusted for clinical and 
instrumental covariates. A p-value $<0.05$ was considered statistically significant.

\section{Results}

Before conventional PM implantation 22 patients were in NYHA Class I, 35 in NYHA Class II and 5 in NYHA Class III. Mean LVEF was $37.0 \pm 8.9 \%$ (range 18 to $60 \%$ ). Normal LV function at 2D Echo (LVEF >or = $50 \%$ ) was reported in 12 patients. All pre conventional PM implantation parameters were extracted by reviewing hospital charts of the studied population.

At time of CRT implantation, average right ventricular stimulation was $>90 \%$ (range 85 to $99 \%$ ). When preupgrading data were compared to pre-conventional pace maker (PM) implantation, a significant worsening in NYHA Class (from $1.9 \pm 1.1$ to $3.2 \pm .6, \mathrm{p}<0.005$ ) along with a decrease in LVEF (from $37.0 \pm 8.9$ to 25.6 $\pm 6.1 \%, \mathrm{p}<0.001$ ), increase in LVEDD (from $60.9 \pm 6.6$ to $65.2 \pm 7.7 \mathrm{~mm}, \mathrm{p}<0.001$ ) and LVESD (from $48.1 \pm$ 8.6 to $55.2 \pm 7.9 \mathrm{~mm}, \mathrm{p}<0.001$ ) were found in the studied population. In the subgroup of patients with a normal LV function before conventional PM implantation LVEF changed from $52.8+3$ to $29.6+6$ (p < 0.0001). In Figure 1 changes in LVEF for each studied patient from pre conventional PM implantation to pre CRT are reported. No relation could be reported between decreased LVEF and the duration of RV apical pacing at time of CRT. Twenty-six patients had a history of myocardial infarction before conventional PM implantation. However, none of the patients had documentation of myocardial infarction or acute coronary syndrome requiring hospitalization before upgrading.

At FU after CRT, NYHA Class decreased to $2.3 \pm 0.5$; a $\geq 1$ NYHA Class improvement was seen in 44/62 patients, 19 with IC and 25 with NIC $(\mathrm{p}<0.005)$. Figure 2.

No myocardial ischemic events from the time of CRT upgrade to the time of FU was documented in this subset of patients.

In the overall population QRS duration decreased from $180 \pm 20$ to $114 \pm 11 \mathrm{msec}(\mathrm{p}<0.01)$. No relation between QRS duration changes, NYHA Class and LVEF increase could be reported in the studied group.

At FU LVEDD changed from $65.2 \pm 7.6$ to $63.3 \pm 7.9$ $\mathrm{mm}(\mathrm{p}<0.1)$, LVESD from $55.2 \pm 7.9$ to $51.2 \pm 8.4 \mathrm{~mm}$ $(\mathrm{p}<0.001)$ and LVEF increased from $25.6 \pm 6.1$ to 31.4 $\pm 9.1 \%(\mathrm{p}<0.001)$. However, a $>10 \%$ decrease in LVESD, as an index of consistent LV reverse remodeling after CRT, was observed in 24 patients only.

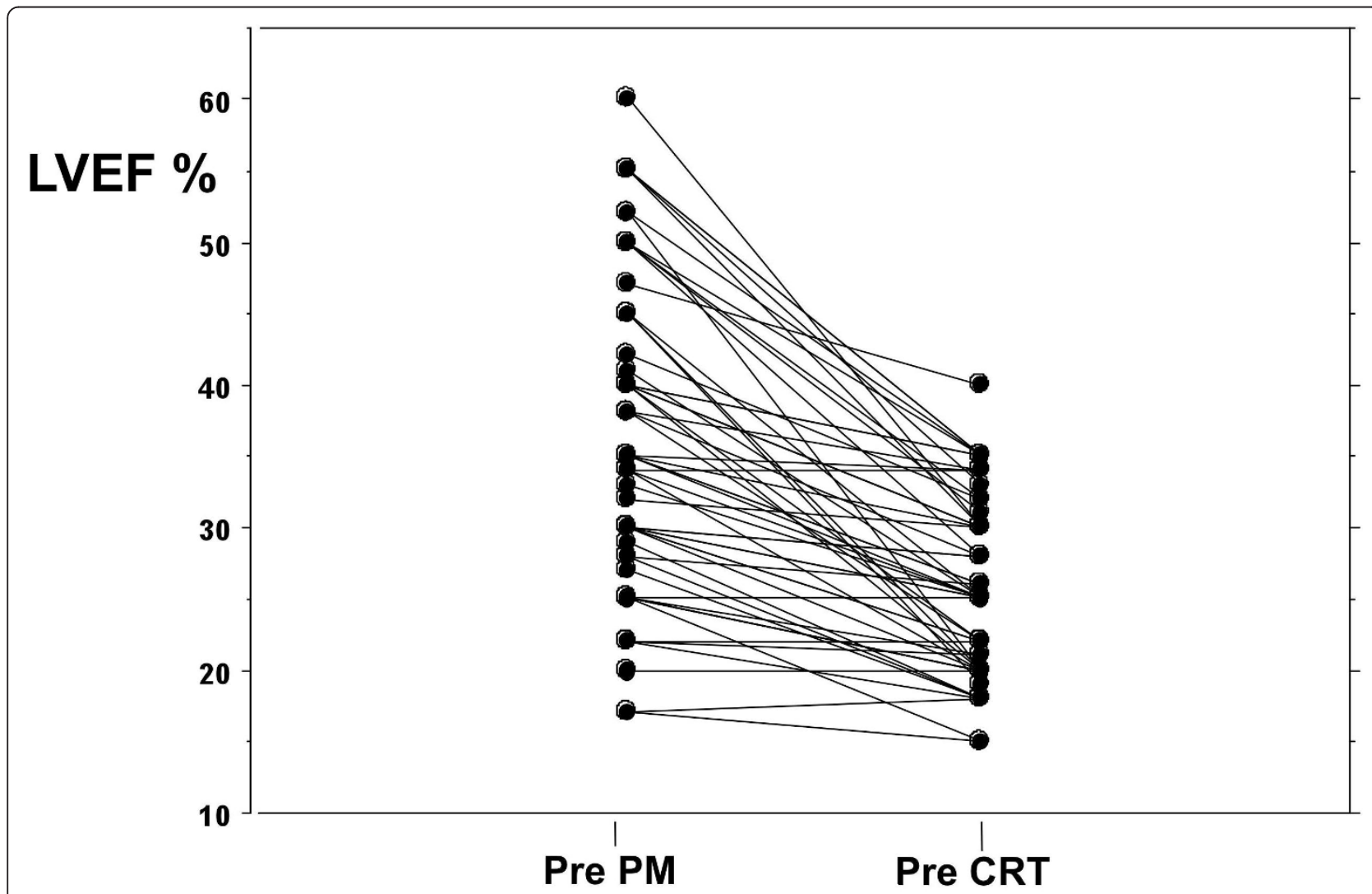

Figure 1 Left ventricular ejection fraction (LVEF\%) changes from pre conventional pacemaker implantation [pre PM] to pre upgrading [pre CRT] in the studied population. 


\section{Changes in NYHA Class}

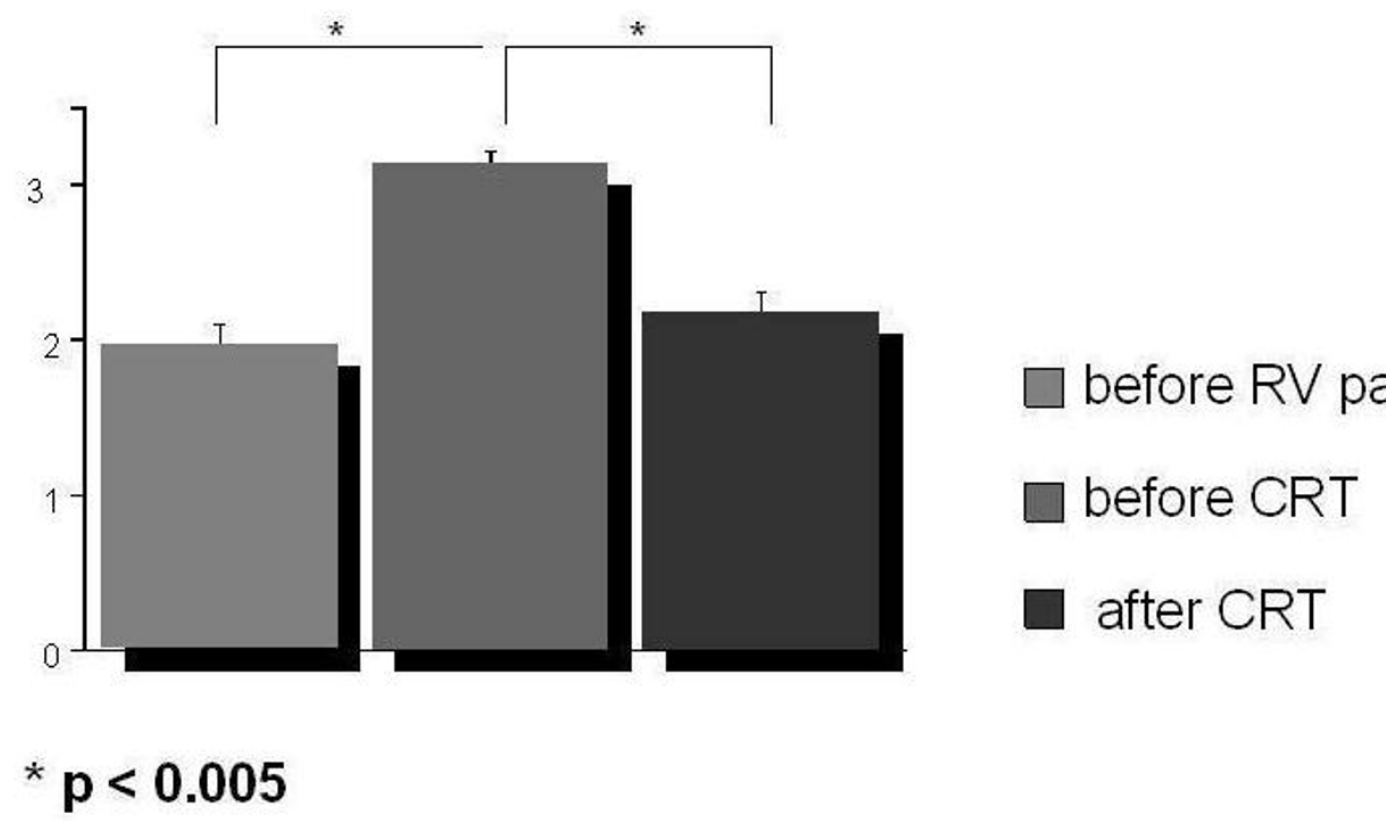

Figure 2 NYHA Class data in the studied patients before RV implantation, before CRT and at FU are reported in the figure.

In table 1 the characteristics of all patients and those with and without reverse remodeling are reported. The only significant difference between the two groups was reported for duration of RV pacing (73 vs 37 months in pts with and without reverse LV remodeling, respectively, $\mathrm{p}<0.01$ ).

As far as mitral regurgitation, the scores calculated before CRT and at follow up changed from $2.3 \pm .8$ to $2.1 \pm .8$, NS; however, when groups were divided according to $>10 \%$ decrease in LVESD, a significant reduction could be reported in the group with reverse remodeling (from $2.2 \pm .6$ to $1.6 \pm .6, \mathrm{p}<0.05$ ) as compared to patients with no significant changes in LVESD (from $2.4 \pm .8$ to $2.4 \pm .7$ ).

In terms of etiology of LV dysfunction, 5/34 patients with IC showed a $>10 \%$ decrease in LVESD compared to $19 / 28$ NIC patients $(\mathrm{p}<0.001)$. Figure 3 .

No differences in pre-CRT QRS duration, NYHA Class, LVEF, LVEDD, LVESD, ongoing treatment, site of LV lead implant, or duration of RV pacing could be observed between the 28 NIC patients vs the 34 IC patients (Table 2). Patients with NIC had a slightly, although not

Table 1 Clinical and echocardiographic characteristics before upgrading of all patients and of those with or without documented $>10 \%$ reduction in LVESD after CRT

\begin{tabular}{|c|c|c|c|c|}
\hline & Total population (n.62) & Reverse remodeling (n.24) & No reverse remodeling (n.38) & $\mathbf{p}$ \\
\hline Age (years) & $73 \pm 7.8$ & $73.4 \pm 8.2$ & $72.6 \pm 7.6$ & NS \\
\hline NYHA Class & $3.2 \pm 0.6$ & $3.2 \pm 0.4$ & $3.2 \pm 0.5$ & NS \\
\hline LVEF (\%) & $25.6 \pm 6.1$ & $26.4 \pm 6.3$ & $25.2 \pm 6.0$ & NS \\
\hline LVEDD (mm) & $65.2 \pm 7.7$ & $65.9 \pm 8.1$ & $64.8 \pm 7.6$ & NS \\
\hline LVESD (mm) & $55.2 \pm 7.9$ & $56.4 \pm 8.4$ & $54.4 \pm 7.6$ & NS \\
\hline Months of RV pacing & $51.2 \pm 38.9$ & $73.2 \pm 57.4$ & $37.3 \pm 38.2 *$ & $P<0.01$ \\
\hline ACE-I or ARB (\%) & 85 & 84 & 86 & \\
\hline Beta blocker (\%) & 90 & 91 & 89 & \\
\hline Diuretics (\%) & 92 & 91 & 93 & \\
\hline
\end{tabular}




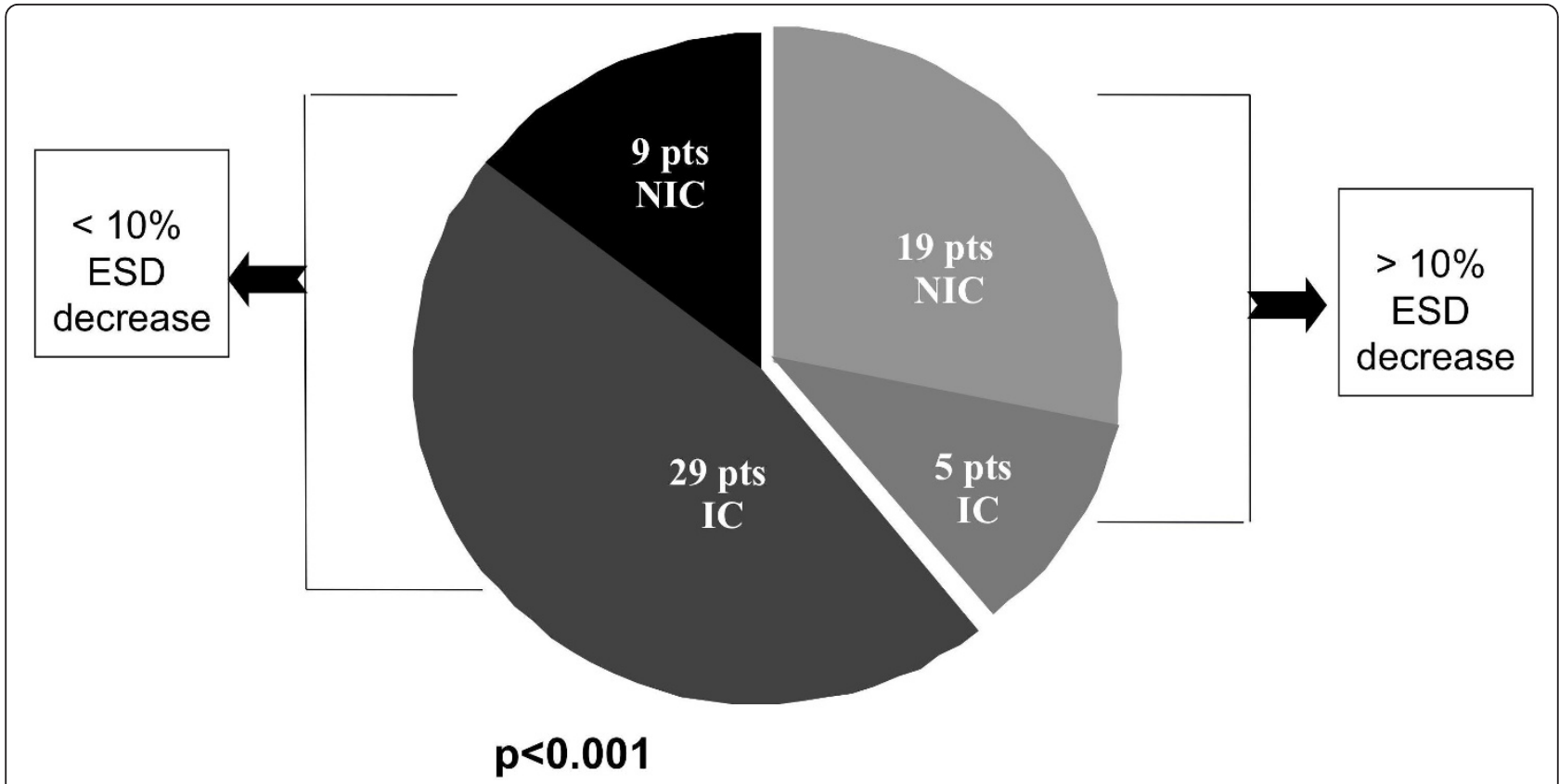

Figure 3 Distribution of patients according to etiology of LV dysfunction and changes in end systolic dimensions (ESD) at FU. IC: ischemic cardiomyopathy; NIC: non ischemic cardiomyopathy.

significant lower WMSI before upgrading, when compared to the IC patients $(2.15 \pm 2.1$ vs $2.26 \pm 2.3)$.

In a multivariate analysis by multiple logistic regression, the association between cause of LV dysfunction with $>10 \%$ LVESD decrease remained highly significant ( $\mathrm{p}<0.001$ ) also adjusting for pre-CRT QRS duration, NYHA Class, LVEF, LVEDD, LVESD, ongoing treatment, site of LV lead implant, or duration of RV pacing. (Table 3).

In the IC group, the 24 patients with documented previous MI had NYHA Class, LVEF and LVESD, WMSI at echocardiography, comparable to those obtained in the 10 patients without MI.

\section{Discussion}

The results of this study confirm previously published data that RV apical pacing may lead to overall reduction

Table 2 Clinical and echocardiographic characteristics before upgrading of patients with IC or NIC

\begin{tabular}{lccc}
\hline & IC (n.28) & NIC (n.34) & p \\
\hline Age (years) & $70.1 \pm 8.0$ & $74.5 \pm 7.3$ & NS \\
NYHA Class & $3.3 \pm 0.5$ & $3.2 \pm 0.4$ & NS \\
LVEF (\%) & $26.0 \pm 6.7$ & $25.3 \pm 5.7$ & NS \\
LVEDD (mm) & $66.9 \pm 8.0$ & $63.8 \pm 7.3$ & NS \\
LVESD (mm) & $56.7 \pm 9.1$ & $54.0 \pm 6.7$ & NS \\
Months of RV pacing & $51.4 \pm 42.4$ & $47.5 \pm 40.9$ & NS \\
\hline
\end{tabular}

LVEF: left ventricular ejection fraction, LVEDD: left ventricular end diastolic dimensions, LVESD: left ventricular end systolic dimensions. RV: right ventricular in LV global function. Upgrading to CRT improved NYHA Class in over $70 \%$ of patients but a significant reduction in LVESD at a mean of 1 year FU was observed in the majority of patients with NIC, while it was less evident in IC patients.

$\mathrm{RV}$ apical pacing is associated with asynchronous electrical activation of the left ventricle which impairs cardiac systolic and diastolic function and induces regional perfusion defects even in the absence of coronary artery disease [22-25].

Upgrading to CRT may determine improvement in clinical symptoms, LV global function and reduces or abolishes dyssynchrony in chronically paced patients $[12,13,16,26,27]$ leading to left ventricular reverse remodeling in a way similar to primary CRT $[14,15]$.

Molhoek et al. demonstrated comparable benefits from primary CRT in patients with ischemic vs nonischemic cardiomyopathy in terms of NYHA Class, quality of life, and LVEF [28]. However, larger studies have shown that NIC patients are more likely to improve clinically and functionally. In the PROSPECT study a greater decrease in LV end systolic volumes was documented in patients with non-ischemic HF when compared to those with an ischemic substrate [29]. Accordingly the MIRACLE and CARE-HF studies showed that reverse LV remodeling occurs to a lesser degree in patients with ischemic etiology [30,31]. Hyperresponders, defined as those who show complete functional recovery up to normalization of LV function after CRT are almost exclusively seen in non-ischemic 
Table 3 Predictors of reverse left ventricular remodeling at univariate and multivariate analysis by Cox model

\begin{tabular}{lcccc}
\hline Variables & Univariate $\mathbf{H R}(\mathbf{9 5} \% \mathbf{C l})$ & P value & Multivariate HR(95\% Cl) & P value \\
\hline NIC & $12.24(3.55-42.18)$ & $<0.001$ & $26.27(0.37-158)$ & $<.001$ \\
QRS duration & $1.02(0.99-1.04)$ & 0.206 & $1.01(0.97-1.05)$ & 0.664 \\
NYHA & $0.99(0.31-3.12)$ & 0.985 & $1.16(0.20-6.68)$ & 0.867 \\
Site of implant PL & $0.69(0.23-2.06)$ & 0.686 & $0.48(0.09-2.71)$ & 0.412 \\
Site of implant A & $0.48(0.08-3.03)$ & 0.435 & $0.06(0.004-1.03)$ & 0.053 \\
RV pacing (mo) & $1.02(1.004-1.03)$ & 0.013 & $1.03(1.01-1.05)$ & 0.012 \\
LVEF & $1.03(0.95-1.12)$ & 0.438 & $1.19(0.97-1.47)$ & 0.101 \\
LVEDD & $1.02(0.95-1.09)$ & 0.589 & $0.76(0.59-0.99)$ & 0.044 \\
LVESD & $1.04(0.97-1.11)$ & 0.299 & $1.35(1.01-1.82)$ & 0.044 \\
\hline
\end{tabular}

Legend: NIC: non ischemic cardiomyopathy. PL: postero-lateral. A: Anterior. Mo: months HR: hazard Ratio. See text for other abbreviations.

cardiomyopathy $[32,33]$. From a pathophysiological point of view, large areas of myocardial scar in ischemic cardiomyopathy may determine complex patterns of LV activation that are not amenable of correction with CRT [34]. In addition, areas of the scar as occurring in post ischemic LV dysfunction may limit LV reverse remodeling after CRT. Therefore, it is understandable that nonischemic HF patients may show LV reverse remodeling to a larger extent than ischemic patients [35].

In this study clinical improvement was reported in a high percentage of patients, comparable to previously published data. Reverse LV remodeling could be found in only 24 patients; of these, 19 had a non-ischemic etiology of underlying LV dysfunction.

In heart failure patients, reversal of LV remodeling after pharmacologic treatment has important prognostic implications, as previously documented in the SOLVD study [36]. Prognosis after CRT was shown to be related to the extent of LV reverse remodeling, more than to clinical response $[33,37,38])$. The definition of LV reverse remodeling is highly variable in literature and changes in LV volumes or diameters have been considered by different AA [29-33]. In line with previously published papers from our group [39] we defined reverse remodelling as a $>10 \%$ reduction in LVESD; low reproducibility and inaccuracy of the methods commonly used for volume calculations by $2 \mathrm{D}$ echocardiography are known, possibly due to the inadvertent use of foreshortened views of the left ventricle and the reliance on geometric modeling [40]. End systolic diameter measurement of is then more reliable, in particular in patients with ischemic dysfunction.

It is important to say that baseline characteristics in NIC and IC were comparable before CRT, in terms of treatment, QRS duration, PM implantation duration, baseline LV function. Interestingly, patients who had been under RV apical pacing for longer periods were those who showed the best functional recovery after upgrading. A possible explanation may be represented by the chronic detrimental effect on LV function provided by right ventricular pacing, which can be reverted by LV resynchronization. Tse et al [9], have shown that long periods of right ventricular pacing result in a high incidence of myocardial perfusion defects. It can be speculated that in these patients upgrading may abolish or attenuate the perfusion defects leading to left ventricular contractile improvement and reduction in end systolic dimensions. In patients in whom upgrading was performed after a short period of RV apical pacing due to clinical and functional worsening, the lack of LV reverse remodeling could have been attributed more to the natural history of the disease, and the correction of dyssynchrony unable to counteract the decline in overall LV function. Another interesting result is represented by the role of LVEDD and LVESD before implant: while LVEDD is a negative factor for LV remodeling after CRT, a bigger LVESD may be a predictor of recovery after upgrading. In a previously published paper, patients who were super responders ( $>30 \%$ reduction in end-systolic volume) and responders after de novo CRT were those showing bigger baseline end-systolic volumes, as compared to patients who functionally worsened at 6 months FU [33].

In conclusion, upgrading to CRT determines improvement in NYHA class in a good percentage of patients. Significant LV reverse remodeling is more likely to occur in patients with non-ischemic cardiomyopathy. Long FU are needed to identify with proper viability/ contractility studies $[41,42]$ patients who may really benefit from upgrading to CRT.

\section{Limitations}

The main limitation of this study is that it is a singlecenter and retrospective cohort study. However clinical data after conventional PM implantation were collected systematically at each programmed out-patient check-up and echocardiograms were analyzed by two reviewers who were blinded to patient name and date of examination. 


\section{Abbreviations}

LV: left ventricle; RV: right ventricle; LVESD: LV end-systolic dimensions; LVEDD: LV end-diastolic dimensions; NIC: Non-ischemic cardiomyopathy; IC Ischemic cardiomyopathy; WMSI wall motion score index; PL: Posterolateral; A: anterior.

\section{Acknowledgements}

The AA wish to thank Ms Alison Frank for her editorial and technical assistance.

\section{Author details}

${ }^{1}$ CNR Clinical Physiology Institute, via G Moruzzi 1, 56124 Pisa, Italy. ${ }^{2}$ Fondazione Toscana Gabriele Monasterio, via G Moruzzi 1, 56124 Pisa, Italy.

\section{Authors' contributions}

MAM Concept/design. US Data analysis. GR Statistics. LP Data collection. AR Data collection. MP Critical revision and approval of the article. All Authors read and approved the final manuscript.

\section{Competing interests}

The authors declare that they have no competing interests.

Received: 28 September 2011 Accepted: 16 December 2011 Published: 16 December 2011

\section{References}

1. Abraham WT, Fisher WG, Smith AL, Delurgio DB, Leon AR, Loh E, Kocovic DZ, Packer M, Clavell AL, Hayes DL, Ellestad M, Trupp RJ, Underwood J, Pickering F, Truex C, McAtee P, Messenger J, MIRACLE Study Group: Multicenter InSync Randomized Clinical Evaluation. Cardiac resynchronization in chronic heart failure. N Engl J Med 2002, 346:1845-1853.

2. Cazeau S, Leclercq C, Lavergne T, Walker S, Varma C, Linde C, Garrigue S, Kappenberger L, Haywood GA, Santini M, Bailleul C, Daubert JC, Multisite Stimulation in Cardiomyopathies (MUSTIC) Study Investigators: Effects of multisite biventricular pacing in patients with heart failure and intraventricular conduction delay. N Engl J Med 2001, 344:873-880.

3. Cleland JG, Daubert JC, Erdmann E, Freemantle N, Gras D, Kappenberger L, Tavazzi L, Cardiac Resynchronization-Heart Failure [CARE-HF] Study Investigators: The effect of cardiac resynchronization on morbidity and mortality in heart failure. N Engl J Med 2005, 352:1539-1549.

4. Rossi A, Rossi G, Startari U, Panchetti L, Piacenti M, Morales MA: The current role of cardiac resynchronization therapy in reducing mortality and hospitalization in heart failure patients. A meta-analysis from clinical trials. Heart Vessels 2008, 4:217-223.

5. Nahlawi M, Waligora M, Spies SM, Bonow RO, Kadish AH, Goldberger JJ: Left ventricular function during and after right ventricular pacing. J Am Coll Cardiol 2004, 44:1883-1888.

6. Sweeney MO, Helkamp AS, Ellenbogen KA, Greenspon AJ, Freedman FA, Lee KL, Lamas GA, for the Mode Selection Trial (MOST) Investigators: Adverse of effects of ventricular pacing on heart failure and atrial fibrillation among patients with normal baseline QRS duration in a clinical trial of pacemaker therapy for sinus node dysfunction. Circulation 2003, 107:2932-2937.

7. Rosenqvist M, Isaaz K, Botvinick EH, Dae MW, Cockrell J, Abbott JA, Schiller NB, Griffin JC: Relative importance of activation sequence compared to atrioventricular synchrony in left ventricular function. Am J Cardiol 1991, 67:148-156.

8. Prinzen FW, Hunter WC, Wyman BT, McVeigh ER: Mapping of regional myocardial strain and work during ventricular pacing: Experimental study using magnetic resonance imaging tagging. J Am Coll Cardiol 1999, 133:1735-1742.

9. Sato-lino $T$, Watanabe $H$, Koyama $T$, lino $K$, Kosaka $T$, Ito H: The prevalence of apical wall motion abnormalities in patients with long-term right ventricular apical pacing. J Am Soc Echocardiogr 2011, 24:556-564.

10. Thackray SD, Witte KK, Nikitin NP, Clark AL, Kaye GC, Cleland JG: The prevalence of heart failure and asymptomatic left ventricular systolic dysfunction in a typical regional pacemaker population. Eur Heart J 2003, 24:1143-1152.
11. Tantengco MV, Thomas RL, Karpawich PP: Left ventricular dysfunction after long-term right ventricular apical pacing in the young. JACC 2001, 37:2093-2100.

12. Witte KK, Pipes RR, Nanthakumar K, Parker JD: Biventricular pacemaker upgrade in previously paced heart failure patients-improvements in ventricular dyssynchrony. J Card Fail 2006, 2:199-204.

13. Horwich T, Foster E, De Marco T, Tseng Z, Saxon L: Effects of resynchronization therapy on cardiac function in pacemaker patients "upgraded" to biventricular devices. J Cardiovasc Electrophysiol 2004, 5:1284-1289.

14. Fröhlich G, Steffel J, Hürlimann D, Enseleit F, Lüscher TF, Ruschitzka F, Abraham WT, Holzmeister J: Upgrading to resynchronization therapy after chronic right ventricular pacing improves left ventricular remodeling. Eur Heart J 2010, 31:1477-1485.

15. Vatankulu MA, Goktekin O, Gurkan Kaya M, Ayhan S, Kucukdurmaz Z, Sutton R, Henein M: Effect of Long-Term Resynchronization Therapy on left Ventricular Remodeling in Pacemaker Patients Upgraded to Biventricular Devices. Am J Cardiol 2009, 103:1280-1284.

16. Dilaveris P, Pantazis A, Giannopoulos G, Synetos A, Gialafos J, Stefanadis C: Upgrade to biventricular pacing in patients with pacing-induced heart failure: can resynchronization do the trick? Europace 2006, 8:352-357.

17. Marsan NA, Bleeker GB, van Bommel RJ, Ypenburg C, Delgado V, Borleffs CJ, Holman ER: Comparison of time course of response to cardiac resynchronization therapy in patients with ischemic versus nonischemic cardiomyopathy. Am J Cardiol 2009, 103:690-694.

18. Wikstrom G, Blomström-Lundqvist $C$, Andren B, Lönnerholm S, Blomström P, Freemantle N, Remp T, Cleland JG, CARE-HF study investigators: on behalf of the CARE-HF study investigators The effects of etiology on outcome in patients treated with cardiac resynchronization therapy in the CARE-HF trial. Eur Heart J 2009, 30:782-788.

19. Morales MA, Startari U, Panchetti L, Rossi A, Piacenti M: Atrioventricular delay optimization by Doppler-derived left ventricular dP/dt improves 6month outcome of resynchronized patients. Pacing Clin Electrophysiol 2006, 29:564-568.

20. Schiller NB, Acquatella $H$, Ports TA, Drew D, Goerke J, Ringertz $H$, Silverman NH, Brundage B, Botvinick EH, Boswell R, Carlsson E, Parmley WW: Left ventricular volume from paired biplane two-dimensional echocardiography. Circulation 1979, 60:547-555.

21. Zoghbi WA, Enriquez-Sarano M, Foster E, Grayburn PA, Kraft CD, Levine RA, Nihoyannopoulos P, Otto CM, Quinones MA, Rakowski H, Stewart WJ, Waggoner A, Weissman NJ, American Society of Echocardiography: Recommendations for evaluation of the severity of native valvular regurgitation with two-dimensional and Doppler echocardiography. J Am Soc Echocardiogr 2003, 16(7):777-802.

22. Kachboura S, Ben Halima A, Fersi I, Marrakchi S, Zouaoui W, Kammoun I: Assessment of heart failure and left ventricular systolic dysfunction after cardiac pacing in patients with preserved left ventricular systolic function. Ann Cardiol Angeiol 2008, 57:29-36.

23. Tse HF, Yu C, Wong KK, Tsang V, Leung YL, Ho WY, Lau CP: Functional abnormalities in patients with permanent right ventricular pacing. The effect of sites of electrical stimulation. J Am Coll Cardiol 2002, 40:1451-1458.

24. Tse HF, Lau CP: Long-term effect of right ventricular pacing on myocardial perfusion and function. J Am Coll Cardiol 1997, 29:744-749.

25. Skalidis El, Kochiadakis GE, Koukouraki SI, Chrysostomakis SI, Igoumenidis NE, Karkavitsas NS, Vardas PE: Myocardial perfusion in patients with permanent ventricular pacing and normal coronary arteries. J Am Coll Cardiol 2001, 37:124-129.

26. Rosen $\mathrm{BD}$, Berger RD: Resynchronization therapy upgrades: turning coach into first class. J Cardiovasc Electrophysiol 2004, 15:1290-1292.

27. Baker CM, Christopher TJ, Smith PF, Langberg JJ, Delurgio DB, Leon AR: Addition of a left ventricular lead to conventional pacing systems in patients with congestive heart failure: feasibility, safety, and early results in 60 consecutive patients. Pacing Clin Electrophysiol 2002, 25:1166-1171.

28. Molhoek SG, Bax JJ, van Erven L, Bootsma M, Boersma E, Steendijk P: Comparison of benefits from cardiac resynchronization therapy in patients with ischemic cardiomyopathy versus idiopathic dilated cardiomyopathy. Am J Cardiol 2004, 93:860-863.

29. van Bommel RJ, Bax JJ, Abraham WT, Chung ES, Pires LA, Tavazzi L, Zimetbaum PJ, Gerritse B, Kristiansen N, Ghio S: Characteristic of heart 
failure patients associated with good and poor response to CRT: a PROSPECT sub analysis. Eur Heart J 2009, 30:2470-2477.

30. Sutton MG, Plappert T, Hilpisch KE, Abraham WT, Hayes DL, Chinchoy E: Sustained reverse left ventricular structural remodeling with cardiac resynchronization at one year is a function of etiology: quantitative Doppler echocardiographic evidence from the Multicenter InSync Randomized Clinical Evaluation (MIRACLE). Circulation 2006, 113:266-72.

31. Ghio S, Freemantle N, Scelsi L, Serio A, Magrini G, Pasotti M, Shankar A, Cleland JG, Tavazzi L: Long term ventricular reverse remodelling with cardiac resynchronization therapy: results from the CARE-HF trial. Eur J Heart Fail 2009, 1:480-488.

32. Castellant P, Fatemi M, Bertault-Valls V, Etienne Y, Blanc JJ: Cardiac resynchronization therapy: "nonresponders" and "hyperresponders". Heart Rhythm 2008, 5:193-197.

33. Ypenburg C, van Bommel RJ, Borleffs CJ, Bleeker GB, Boersma E, Schalij MJ Bax JJ: Long-Term prognosis after cardiac resynchronization therapy is related to the extent of left ventricular reverse remodeling at midterm follow-Up. J Am Coll Cardiol 2009, 53:483-490.

34. Sweeney MO, Prinzen FW: Ventricular pump function and pacing: physiological and clinical integration. Circ Arrhythm Electrophysiol 2008, 1:127-39.

35. Ypenburg C, Roes SD, Bleeker GB, et al: Effect of total scar burden oncontrast-enhanced magnetic resonance imaging on response to cardiac resynchronization therapy. Am J Cardiol 2007, 99:657-60

36. Konstam MA, Kronenberg MW, Rousseau MF, Udelson JE, Melin J, Stewart D, Dolan N, Edens TR, Ahn S, Kinan D, Howe DM, Kilcoyne L, Metherall J, Benedict C, Yusuf S, Pouleur H, for the SOLVD investigators: Effects of angiotensin converting enzyme inhibitor ebalapril on the long-term progression of left ventricular dysfunction in patients with heart failure. Circulation 1992, 86:431-438,

37. Woo GW, Petersen-Stejskal S, Johnson JW, Conti JB, Aranda JA Jr, Curtis AB: Ventricular reverse remodeling and 6-month oucomes in patient receiving cardiac resynchronization therapy: analysis of the MIRACLE study. J Interv Card Electrophysiology 2005, 12:107-113.

38. Yu CM, Bleeker GB, Fung JW, Schalij MJ, Zhang Q, van der Wall EE, Chan YS, Kong SL, Bax JJ: Left ventricular reverse remodeling but not clinical improvement predictslong-term survival after cardiac resynchronization therapy. Circulation 2005, 112:1580-1586.

39. Morales MA, Maltinti M, Piacenti M, Turchi S, Giannessi D, Del Ry S: Adrenomedullin plasma levels predict left ventricular reverse remodeling after cardiac resynchronization therapy. Pacing Clin Electrophysiol 2010, 33:865-72.

40. Caiani EG, Corsi C, Zamorano J, Sugeng L, MacEneaney P, Weinert L, Battani R, Gutierrez JL, Koch R, Perez de Isla L, Mor-Avi V, Lang RM: Improved semi-automated quantification of left ventricular volumes and ejection fraction using high-resolution real-time three-dimensional echocardiography: comparison with MRI. J Am Soc Echocardiogr 2005, 18:779-788,

41. Ciampi Q, Pratali L, Citro R, Villari B, Picano E, Sicari R: Clinical and prognostic role of pressure-volume relationship in the identification of responders to cardiac resynchronization therapy. Am Heart J 2010, 160(5):906-14.

42. Moonen M, Senechal M, Cosyns B, Melon P, Nellessen E, Pierard L, Lancellotti P: Impact of contractile reserve on acute response to cardiac resynchronization therapy. Cardiovasc Ultrasound 2008, 6:65.

doi:10.1186/1476-7120-9-41

Cite this article as: Morales et al:: Reverse left ventricular remodeling is more likely in non ischemic cardiomyopathy patients upgraded to biventricular stimulation after chronic right ventricular pacing. Cardiovascular Ultrasound 2011 9:41.

\section{Submit your next manuscript to BioMed Central and take full advantage of:}

- Convenient online submission

- Thorough peer review

- No space constraints or color figure charges

- Immediate publication on acceptance

- Inclusion in PubMed, CAS, Scopus and Google Scholar

- Research which is freely available for redistribution

Submit your manuscript at www.biomedcentral.com/submit
Biomed Central 